\title{
Sintering Behavior of Cobalt Oxide Doped Ceria Powders of Different
}

\section{Particle Sizes}

\section{Journal Article}

\section{Author(s):}

Jud, Eva; Gauckler, Ludwig J.

Publication date:

2005

\section{Permanent link:}

https://doi.org/10.3929/ethz-b-000032480

\section{Rights / license:}

In Copyright - Non-Commercial Use Permitted

\section{Originally published in:}

Journal of electroceramics 14(3), https://doi.org/10.1007/s10832-005-0964-5 


\title{
Sintering Behavior of Cobalt Oxide Doped Ceria Powders of Different Particle Sizes
}

\author{
EVA JUD \& LUDWIG J. GAUCKLER \\ Nonmetallic Inorganic Materials, Department of Materials, Swiss Federal Institute of Technology, ETH Zurich, \\ CH-8093 Zurich, Switzerland
}

Submitted August 24, 2004; Revised December 23, 2004; Accepted December 28, 2004

\begin{abstract}
The effect of cobalt oxide as sintering aid for $\mathrm{CeO}_{2}$ and $\mathrm{Ce}_{0.9} \mathrm{Gd}_{0.1} \mathrm{O}_{1.95}$ powders was studied as a function of initial powder particle size. The sintering effect of cobalt oxide, measured as the difference in temperature of maximum shrinkage rate between undoped and 1 cat $\%$ cobalt oxide doped powders, decreased with initial particle size. Almost no effect was found for the smallest particle sizes investigated $(d<10 \mathrm{~nm})$ whereas the maximum shrinkage rate temperature decreases by more than $200^{\circ} \mathrm{C}$ for particles $d>100 \mathrm{~nm}$. For the smaller particles, only doping of much higher concentration produces significant decreases in the temperature of maximum shrinkage rate. This observation suggests that the effectiveness of sintering depends on the specific surface area of the starting powder and points at the decisive role of the doping method used. Dense microstructures with average grain sizes smaller than $100 \mathrm{~nm}$ are obtained by doping very fine powders with cobalt oxide.
\end{abstract}

Keywords: sintering, dilatometry, ceria solid solutions, cobalt oxide doping, small particle size

\section{Introduction}

The addition of small amounts of a dopant to improve the sintering process of metallic as well as ceramic powders is an established method. Two types of additives need to be distinguished. A first group of additives are solid solution additives, which dissolve in the host material. The solute typically decreases the grain boundary mobility, so that higher sintering densities are achieved. The addition of $\mathrm{MgO}$ to $\mathrm{Al}_{2} \mathrm{O}_{3}$ is the seminal and probably best understood case as it made the fabrication of fully densified alumina possible [1]. Subsequently, many other materials, such as $\mathrm{MgO}, \mathrm{Y}_{2} \mathrm{O}_{3}$, or $\mathrm{ZnO}$, could successfully be sintered by using the solid solution approach [2]. The second group of additives exhibits only limited solubility in the host material and therefore resides mainly at the grain boundaries. Depending on the processing temperature, this additional phase may either lead to liquid phase sintering or to activated solid state sintering. Both approaches have in common that diffusion across and in the grain boundary is enhanced, in the first case by a liquid bridge and in the second by a thin grain boundary layer. If the phase diagram of a materials system is known in sufficient detail, the optimal processing parameters can be determined experimentally within a reasonable time frame. In case of activated solid state sintering, the knowledge of the corresponding phase diagram can also be a helpful tool. In many cases however, phase diagrams are not known in sufficient detail and more over, activated solid state sintering is usually found below the eutectic temperature [3]. German et al. have established a list of criteria for material systems to be suited for activated sintering [4]. For a suitable system, a first requirement is a higher solubility of the host in the additive material than vice versa. If a certain solubility of the additive in the host exists, the activation may become transient. A decrease of liquidus and solidus as the host is alloyed is required in addition to promote segregation of the equilibrium second phase. Further desirable is a system with low eutectic temperatures and therefore high diffusivities at the boundary.

These criteria have been validated amongst others for the case of Ni-doped W [4]. Transition metals in general have proven to be suitable dopants for activated sintering of various refactory metals, such as 
molybdenum, tungsten, chromium, rhenium, and tantalum [5]. Increased density improves desirable physical and mechanical properties of sintered materials in general. However, the increased diffusion rates at the boundary promote also grain growth, which may degrade the sintered density again [6]. A well investigated ceramic system, which has shown properties of activated sintering is $\mathrm{Bi}_{2} \mathrm{O}_{3}$-doped $\mathrm{ZnO}$. The addition of $\mathrm{Bi}_{2} \mathrm{O}_{3}$ leads to liquid phase sintering at temperatures above $740^{\circ} \mathrm{C}$, the eutectic temperature of the system $\mathrm{ZnO}-\mathrm{Bi}_{2} \mathrm{O}_{3}$ [7]. But significant shrinkage even sufficient to reach full density was also observed below the eutectic temperature in isothermal sintering experiments [8]. At high temperatures, the presence of $\mathrm{Bi}_{2} \mathrm{O}_{3}$ causes enhanced grain growth of the $\mathrm{ZnO}$ matrix already at an additive concentration of $0.05 \mathrm{~mol} \%$ [7, 9]. Recently, Luo et al. have observed disordered grain surfaces and intergranular films with 1-2 nm thickness below and above the eutectic temperature [10]. They assigned the phenomenon of activated sintering below the eutectic temperature to the existence of these amorphous intergranular films [11].

Transition metal oxides (e.g. $\mathrm{MnO}_{2}, \mathrm{Fe}_{2} \mathrm{O}_{3}, \mathrm{Co}_{3} \mathrm{O}_{4}$, $\mathrm{NiO}, \mathrm{CuO}$ ) have also shown properties of improved sintering for ceria and zirconia based solid solutions [1216] below the eutectic temperature [17]. In all studies, increased shrinkage rates at relative low temperatures and reduced maximum sintering temperatures have been observed. In the case of cobalt oxide doped $\mathrm{Ce}_{0.8} \mathrm{Gd}_{0.2} \mathrm{O}_{1.9}$, the improved sintering properties could be assigned to a grain boundary film acting as a short circuit path resulting in improved densification, but also in enhanced grain growth [18, 19]. On the other hand, very little grain growth was observed during sintering since grain sizes in the sub-micron range $(\sim 120 \mathrm{~nm})$ could be achieved $[12,20]$. The observation of little grain growth indicates that rearrangement of particles, due to reduced interparticle friction, is important during densification. Zhang et al. investigated the sintering of Fe-doped $\mathrm{CeO}_{2}$ [21]. They found that the grain boundary film formed by the additive reduces the interparticle friction leading to a viscous flow mechanism. These results strongly suggest that the sintering of transition metal oxide doped ceria solid solutions is dominated by a viscous flow mechanism in the early sintering stage while activated sintering plays an important role in the final sintering stage.

The amount of activator material necessary to change the sintering properties of the host material is small and usually below 3 cat $\%$ of the dopant. The more homogeneously the dopant is distributed in the matrix, the more pronounced the effect is. In the case of Ni-doped $\mathrm{W}$, it was shown that a small particle size of the dopant could increase the promoting sintering effect [22]. Decreasing the particle size of the host material to the nanometer range can also help to enhance the overall sintering properties [23, 24]. Hence, the aim of this study is to explore the combined effects of high specific surface area of the host material and the addition of a dopant for the case of cobalt oxide doped ceria solid solutions.

\section{Experimental Procedures}

Commercially available ceria and ceria gadolinium oxides (CGO) of various particle size were used. In order to further enlarge the range and cover several orders of magnitude of particle sizes, selected very fine powders were calcined. Calcination temperatures were chosen low enough, so that the formation of hard agglomerates was avoided. Powder particle sizes were characterized by BET measurements (Nova1000, Quantachrome, Germany), SEM (LEO 1530, Germany), TEM, X-ray diffraction (XRD-Diffractometer D 5000, Siemens, Germany) combined with Rietveld refinement (TOPAS R 2.0, Bruker AXS, Germany). Most powders were doped with 1 cat $\%$ of cobalt oxide. The powders were ultrasonically dispersed in ethanol and the desired amount of cobalt nitrate hexahydrate dissolved in ethanol was added. After an additional ultrasonication, the solvent was evaporated and the powder dried at $120^{\circ} \mathrm{C}$. The nitrate was converted to cobalt oxide by calcining at $400^{\circ} \mathrm{C}$ for $4 \mathrm{~h}$. Green compacts were fabricated by isostatic pressing at $300 \mathrm{MPa}$ for $3 \mathrm{~min}$. Pressureless sintering was conducted in a horizontal dilatometer (Type 802S, Bähr Thermoanalyse GmbH, Germany). Before and after sintering, the density was determined by the Archimedes method. Microstructures were obtained by polishing down to $1 \mu \mathrm{m}$ diamond paste. After thermal etching $20^{\circ} \mathrm{C}$ below the respective maximum sintering temperature, the grain size was determined based on SEM images measuring at least 300 grains. A mean intercept length to mean grain size conversion factor of 1.56 was used [25].

\section{Results and Discussion}

The provenience of all powders and where applicable the calcination temperature is listed in Table 1 . 
Table 1. Powder description.

\begin{tabular}{llc}
\hline Powder & Source & Calcination \\
\hline $1 \mathrm{CeO}_{2}$ & MicroCoating Technologies, USA & \\
$2 \mathrm{CeO}_{2}$ & Alfa Aesar, Johnson Matthey GmbH, D & \\
$3 \mathrm{CeO}_{2}$ & Alfa Aesar, Johnson Matthey GmbH, D & \\
$4 \mathrm{CeO}_{2}$ & Auerweiss Typ BF, Treibacher Auermet, A & \\
$1 \mathrm{CGO}$ & MicroCoating Technologies, USA & $1 \mathrm{CGO} 2 \mathrm{~h}$ \\
$2 \mathrm{CGO}$ & MicroCoating Technologies, USA & at $750^{\circ} \mathrm{C}$ \\
& & \\
$3 \mathrm{CGO}$ & Rhodia, Catalysis \& Electronics, F & $3 \mathrm{CGO} 2 \mathrm{~h}$ \\
$4 \mathrm{CGO}$ & Rhodia, Catalysis \& Electronics, F & at $800^{\circ} \mathrm{C}$ \\
& & $3 \mathrm{CGO} 2 \mathrm{~h}$ \\
$5 \mathrm{CGO}$ & Rhodia, Catalysis \& Electronics, F & at $1000^{\circ} \mathrm{C}$ \\
& &
\end{tabular}

Table 2. Powder characterization.

\begin{tabular}{lccl}
\hline Powder & $d_{\text {BET }}(\mathrm{nm})$ & $d_{\text {SEM/TEM }}(\mathrm{nm})$ & $d_{\text {XRD }}(\mathrm{nm})$ \\
\hline $1 \mathrm{CeO}_{2}$ & 6.6 & 21 & $10(78 \%), 27(22 \%)$ \\
$2 \mathrm{CeO}_{2}$ & 11 & 57 & $16(66 \%), 86(34 \%)$ \\
$3 \mathrm{CeO}_{2}$ & 92 & 208 & $>100$ \\
$4 \mathrm{CeO}_{2}$ & 290 & 416 & $>100$ \\
$1 \mathrm{CGO}$ & 6.2 & 10 & $4.5(88 \%), 9.0(12 \%)$ \\
$2 \mathrm{CGO}$ & 11 & 24 & 14 \\
$3 \mathrm{CGO}$ & 24 & 54 & 20 \\
$4 \mathrm{CGO}$ & 58 & 62 & 34 \\
$5 \mathrm{CGO}$ & 137 & 100 & $>100$ \\
\hline
\end{tabular}

The results regarding the powder characterization by BET, microscopy, and X-ray diffraction of all $\mathrm{CeO}_{2}$ and $\mathrm{Ce}_{0.9} \mathrm{Gd}_{0.1} \mathrm{O}_{1.95}$ (CGO) powders are given in Table 2 . Since the calculation of the equivalent particle diam-

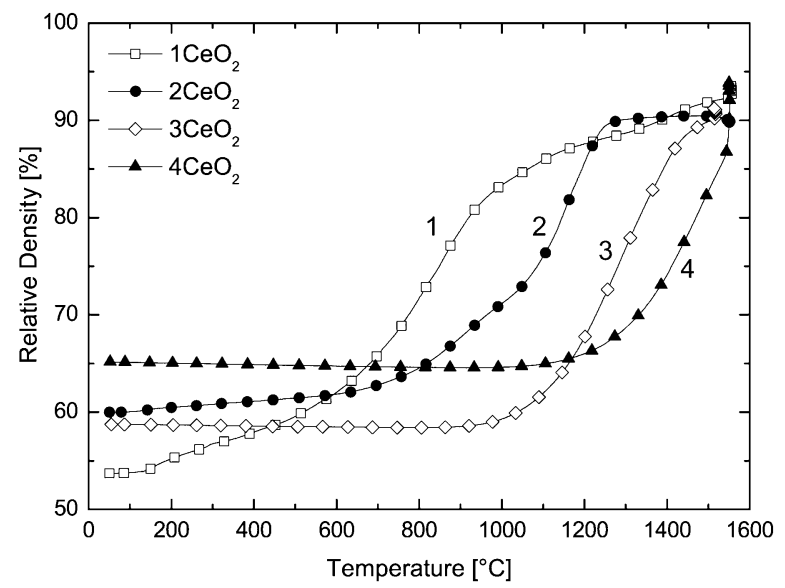

(a) eter $d_{\mathrm{BET}}$ from the BET measurement is based on the assumption of spherical particles, the effective diameter is generally underestimated. This discrepancy can be deduced from Table 2 , where all $d_{\mathrm{BET}}$ values are smaller than the corresponding particle sizes evaluated by SEM. The particle sizes of the smallest powders $\left(1 \mathrm{CeO}_{2}\right.$ and $\left.1 \mathrm{CGO}\right)$ have been obtained from TEM images provided by the manufacturer. For powders with particles sizes below $100 \mathrm{~nm}$, the diameters $d_{\text {SEM }}$ are much larger than the $d_{\mathrm{BET}}$ values. This difference is due to the limited resolution of the SEM. For powders $1 \mathrm{CeO}_{2}, 2 \mathrm{CeO}_{2}$, and $1 \mathrm{CGO}$, the crystallite sizes calculated by the Rietveld refinement show evidence of bimodal particle size distributions. Relative fractions are indicated in parentheses. Further, the crystallite size can be smaller than the particle size deduced from BET if a particle consists of several crystallites. Yet, if particles consist of one crystallite, $d_{\mathrm{XRD}}$ is usually larger than $d_{\mathrm{BET}}$ since the BET method is surface area based whereas X-ray diffraction is a mass dependent method [26]. As expected, doping with 1 cat $\%$ of cobalt oxide does not change the specific surface area of the powder significantly. The same particle sizes have therefore been used in the following analysis for the undoped as well as for the doped powders.

Figs. 1 and 2 show the results of the dilatometric measurements for all $\mathrm{CeO}_{2}$ and $\mathrm{CGO}$ powders (undoped and doped with 1 cat $\%$ cobalt oxide) obtained by constant heating rate sintering. Pressed powder compacts possess different green densities due to different powder geometries. A higher green density is usually obtained with powders of larger particle size as can

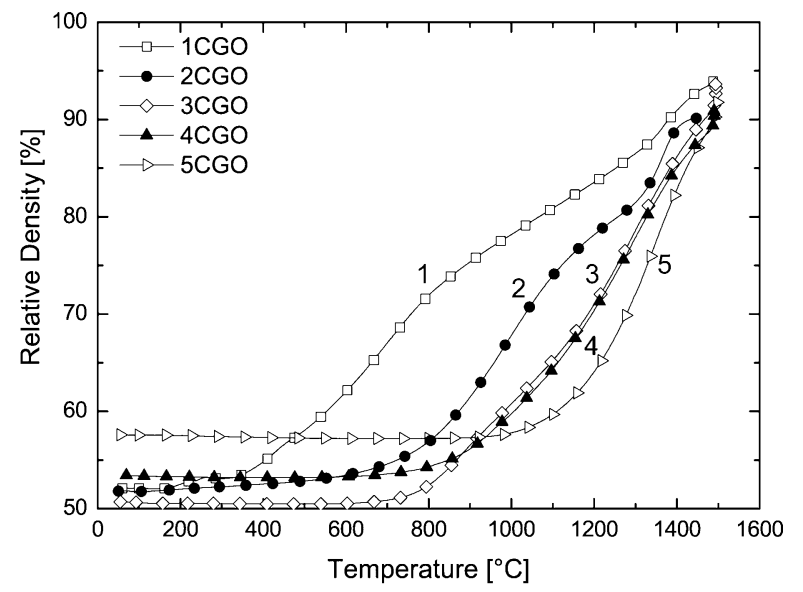

(b)

Fig. 1. Relative density as a function of temperature at a heating rate of $5^{\circ} \mathrm{C} / \mathrm{min}$ for (a) $\mathrm{CeO}_{2}$ and (b) $\mathrm{CGO}$ powders. 


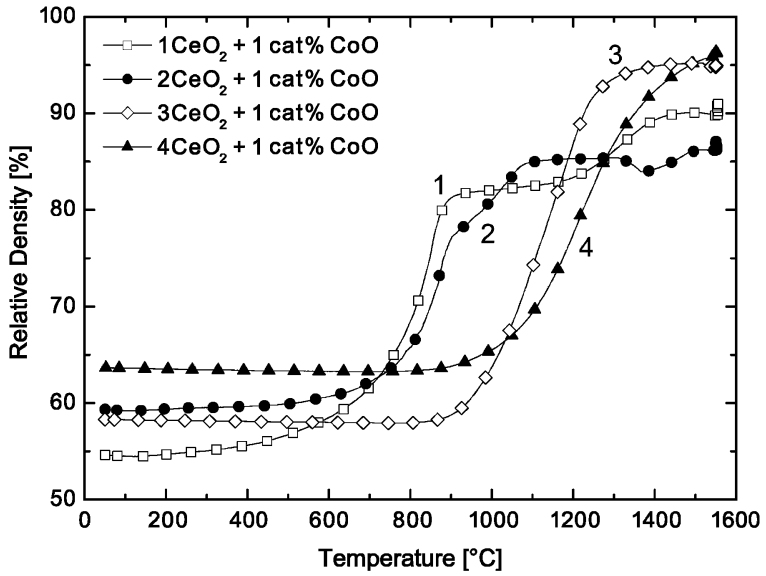

(a)

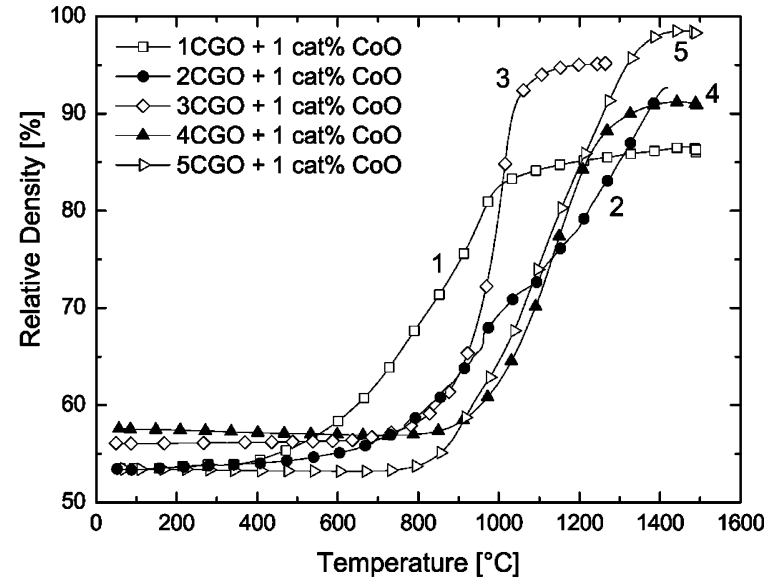

(b)

Fig. 2. Relative density as a function of temperature at a heating rate of $5^{\circ} \mathrm{C} / \mathrm{min}$ for (a) $\mathrm{CeO}_{2}$ and (b) $\mathrm{CGO}$ powders doped with 1 cat $\%$ of cobalt oxide.

clearly be seen by comparing $1 \mathrm{CeO}_{2}$ with $4 \mathrm{CeO}_{2}$ for example. In case of the doped powders, the relative differences in green densities are smaller. The effect of the specific surface area on the respective sintering behavior is obvious. Powders that have a high specific surface area and therefore a high driving force for sintering, start to densify at a lower temperature. In addition, they also reach the maximum shrinkage rate already at a lower temperature. Table 3 shows the temperature of maximum shrinkage rate for all powders. Some powders exhibit two maxima in the shrinkage rate, which can be attributed to a bimodal particle size distribution or to a bimodal pore size distribution. Powder $2 \mathrm{CeO}_{2}$ for example shows two sintering maxima, which can be correlated to the bimodal particle size dis-

Table 3. Sintering characteristics of undoped and $\mathrm{CoO}-$ doped powders.

\begin{tabular}{lll}
\hline Powder & $\begin{array}{l}\text { Temperature of }(\mathrm{d} \rho / \mathrm{d} T)_{\max } \\
\text { undoped }\left({ }^{\circ} \mathrm{C}\right)\end{array}$ & $\begin{array}{l}\text { Temperature of }(\mathrm{d} \rho / \mathrm{d} T)_{\max } \\
\text { doped with } 1 \mathrm{cat} \% \mathrm{CoO}\left({ }^{\circ} \mathrm{C}\right)\end{array}$ \\
\hline $1 \mathrm{CeO}_{2}$ & $845 / 1410$ & $850 / 1330$ \\
$2 \mathrm{CeO}_{2}$ & $920 / 1160$ & $870 / 1020$ \\
$3 \mathrm{CeO}_{2}$ & 1290 & 1150 \\
$4 \mathrm{CeO}_{2}$ & 1480 & 1210 \\
$1 \mathrm{CGO}$ & $685 / 1366$ & $954 / 757$ \\
$2 \mathrm{CGO}$ & $985 / 1365$ & $962 / 1344$ \\
$3 \mathrm{CGO}$ & 971 & 924 \\
$4 \mathrm{CGO}$ & 1298 & 1096 \\
$5 \mathrm{CGO}$ & 1344 & 1139 \\
\hline
\end{tabular}

tribution measured by X-ray diffraction, but also to the bimodal pore size distribution measured by mercury intrusion porosimetry shown in Fig. 3. This correlation also demonstrates the limited information contained in the particle size characterisation shown in Table 2. Particles sizes can only give a first idea about the expected sintering properties. In order to actually predict the shape of a densification curve, a more complete description of the green body microstructure is required. Pore size distributions measured by mercury intrusion also define only one aspect of the green body characteristics. A similar observation is that the particle size can not be correlated with the final densities of the sintered powder compacts as obvious from the results presented in Figs. 1 and 2. Nevertheless, it can be seen that powders of large particle size continue to densify during the dwell at high temperature (see e.g. $4 \mathrm{CeO}_{2}$ ) whereas powders of small particle size reach their final density at lower temperature (see e.g. $2 \mathrm{CeO}_{2}$ ). The low final densities found for compacts of the small powders are amongst other reasons consequence of the measurement method, i.e. the reference of theoretical density is changing. Final densities decrease at high temperatures mainly due to the reduction of $\mathrm{Ce}^{4+}$ to $\mathrm{Ce}^{3+}$ leading to the formation of oxygen vacancies. Since the densification curves are adjusted according to the measured density by Archimedes, the effective loss in density at high temperatures remains indiscernible.

The effect of cobalt oxide doping on the temperature of maximum shrinkage rate becomes obvious in 


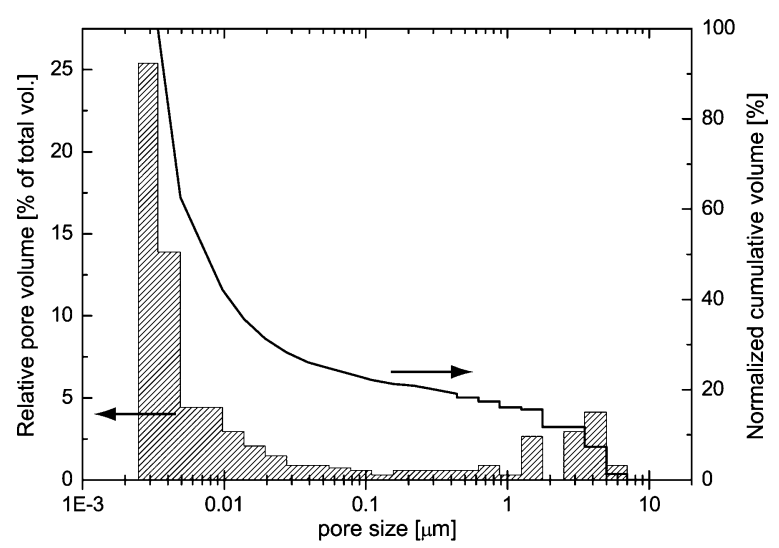

Fig. 3. Pore size distribution of green body of powder $2 \mathrm{CeO}_{2}$.

Table 3. Except for the smallest powders, doping decreases the temperature of maximum shrinkage rate. The effect is more pronounced for large particle sizes as Fig. 4 demonstrates, where the temperature of maximum shrinkage rate is plotted as a function of initial particle size. For most powders, $d_{\mathrm{BET}}$ has been taken as the value of initial particle size, but for powders $1 \mathrm{CeO}_{2}$ and $2 \mathrm{CeO}_{2}$, the crystallite sizes have been used. Also, the second maxima in the shrinkage rates of compacts from powders $1 \mathrm{CeO}_{2}, 1 \mathrm{CGO}$, and $2 \mathrm{CGO}$ have been neglected since they might correspond to sizes of agglomerates. It is clearly seen in Fig. 4 that for large particles, the temperature of maximum shrinkage rate may differ by as much as $300^{\circ} \mathrm{C}$. The differences become smaller with decreasing particle sizes. In the case

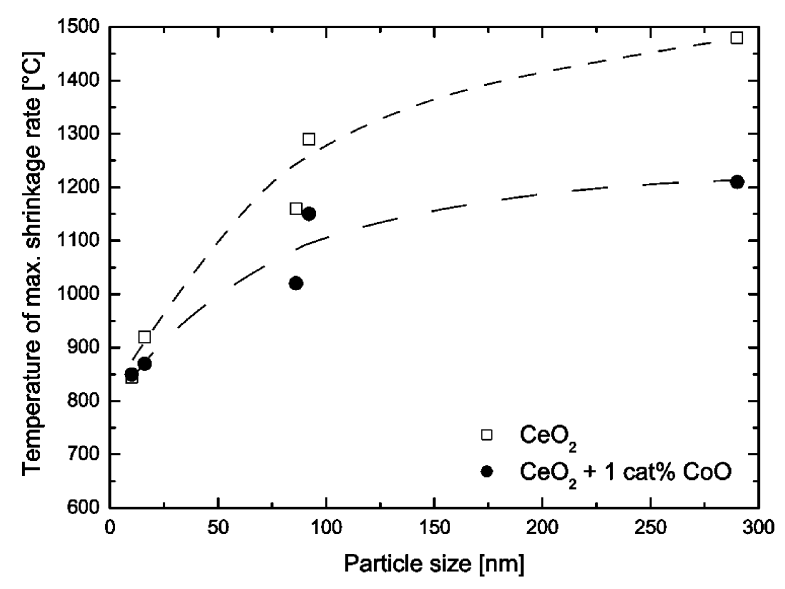

(a) of CGO, even a crossover for the smallest particles size is observed. Evidently, doping has a detrimental effect on the sintering behavior. This surprising result motivated further investigation.

To this end, 1CGO was doped with increasing concentrations of cobalt oxide up to 10 cat $\%$. The shrinkage rate of compacted powders was measured in the dilatometer and are displayed in Fig. 5. It can clearly be seen that the temperature of maximum shrinkage rate is the lowest for a doping concentration of 5 cat $\%$. Higher concentrations, such as 10 cat $\%$ are less favourable to the sintering process increasing the temperature of maximum shrinkage rate and decreasing the maximum shrinkage rate. Analog observations have been made in a previous work [12]. It must be concluded that for the presently used method of doping, a fine powder, such as $1 \mathrm{CGO}$ requires a higher dopant concentration than 1 cat $\%$ in order to produce the most distinct sintering effect. For an explanation, one should consider how dramatically the specific surface area of a powder increases if the particle size reaches the nanometer range. Then, the homogeneous distribution of small amounts of dopant material over the large surface area becomes a critical processing parameter and increasingly depending on the doping method used. For a given method, higher doping concentrations are needed to achieve contact of all particles with sufficient doping material. Alternatively, a more suitable doping method might be developed ensuring homogeneous coverage of all particles. With improved doping methods, it can be expected that the temperature of maximum shrinkage

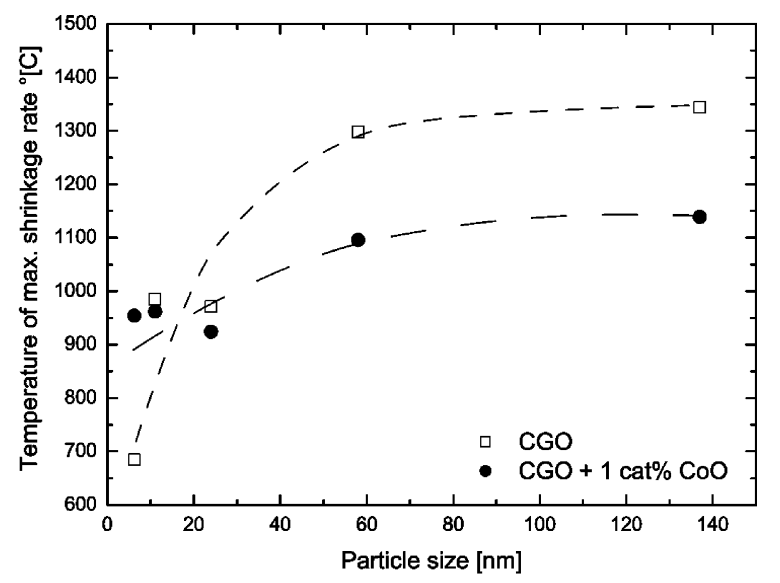

(b)

Fig. 4. Temperature of maximum shrinkage rate as a function of powder particle size for (a) $\mathrm{CeO}_{2}$ and (b) $\mathrm{CGO}$, undoped as well as doped with 1 cat\% of cobalt oxide. Dashed lines serve as guide for the eye. 


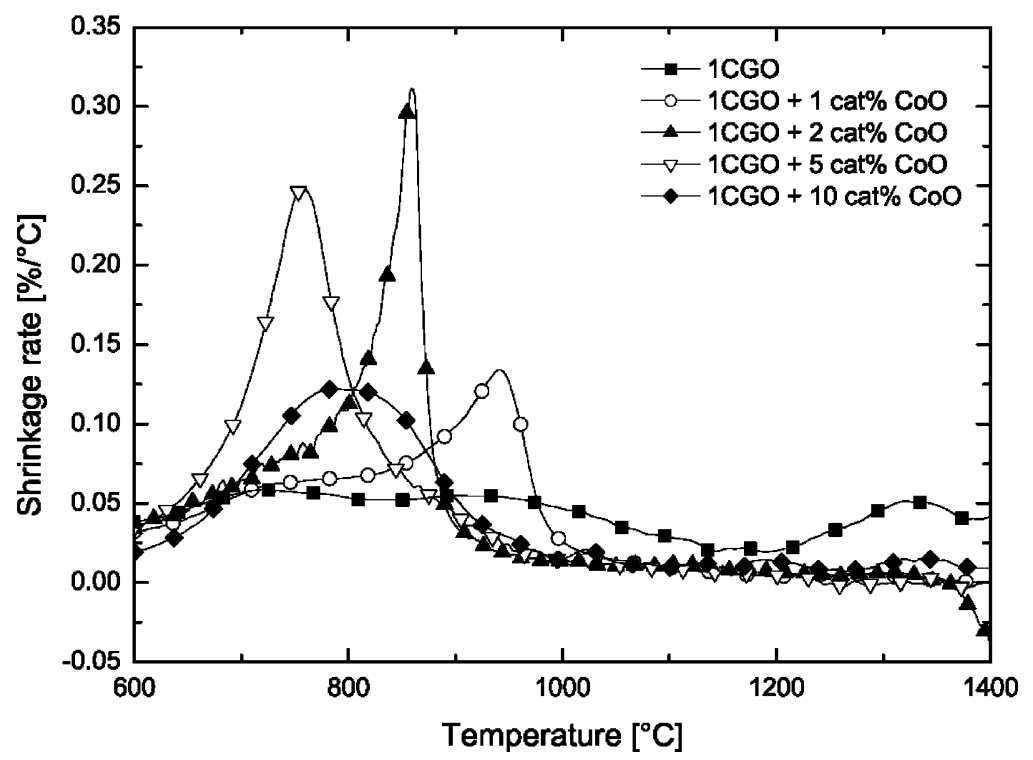

Fig. 5. Shrinkage rate as a function of temperature for powder 1CGO doped with various concentrations of cobalt oxide.

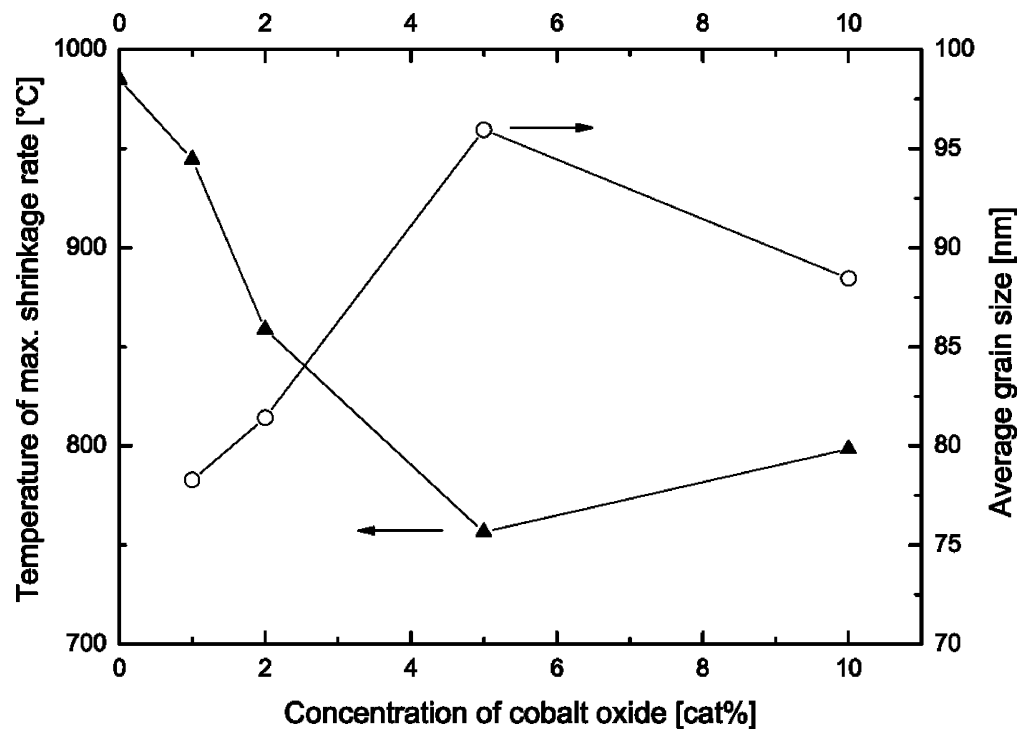

Fig. 6. Temperature of maximum shrinkage rate and average grain size depending on the doping content of cobalt oxide for powder 1CGO. Average grain sizes have been measured in samples sintered at $900^{\circ} \mathrm{C}$ for $2 \mathrm{~h}$.

will decrease even for very small particles and consequently, no need for higher doping concentration arises.

In Fig. 6, the temperature of maximum shrinkage rate and the average grain size is plotted as a function of doping content. The measured average grain sizes show that enhanced grain growth is concurrently observed with densification confirming the observation that cobalt oxide promotes grain growth [19]. Nevertheless, the use of a fine powder such as 1CGO combined with the effect of cobalt oxide permits the fabrication of very fine and dense microstructures with average grain sizes below $100 \mathrm{~nm}$. Fig. 7 shows the microstructure of powder 1CGO doped with 1 cat $\%$ cobalt oxide sintered at $900^{\circ} \mathrm{C}$ for $2 \mathrm{~h}$. The average grain size was found 


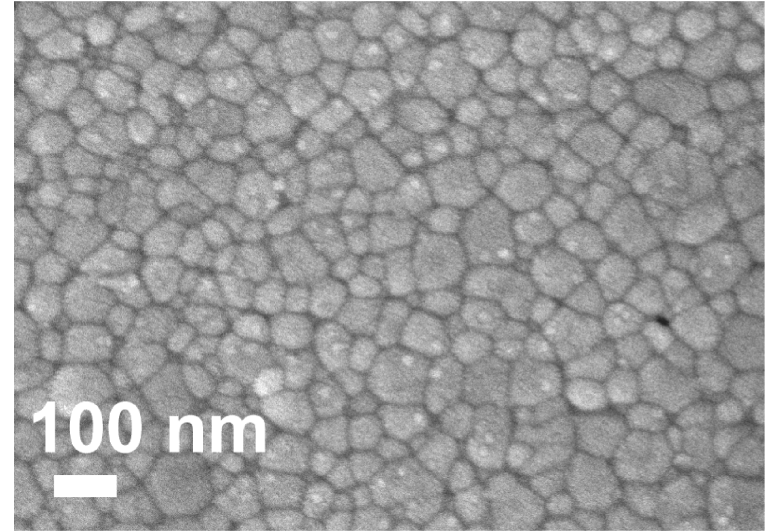

Fig. 7. Microstructure of powder $1 \mathrm{CGO}$ doped with 1 cat $\% \mathrm{CoO}$ sintered at $900^{\circ} \mathrm{C}$ for $2 \mathrm{~h}$.

to be $78 \mathrm{~nm}$, which corresponds to a growth factor of roughly 13 .

\section{Conclusion}

Commercial $\mathrm{CeO}_{2}$ and $\mathrm{Ce}_{0.9} \mathrm{Gd}_{0.1} \mathrm{O}_{1.95}$ powders of particle sizes ranging from 6.6 to $416 \mathrm{~nm}$ have been doped with 1 cat $\%$ of cobalt oxide and their sintering properties studied. Powders of small particles size exhibiting a high driving force for sintering started to densify at lower temperature. With cobalt oxide doping, increased shrinkage rates and decreased sintering temperatures due to the doping were observed for all powders except for small powders. In general, the doping effect, measured as the difference in temperature of maximum shrinkage rate, decreased with particle size, but showed almost no if not a deterioring effect for the smallest powders of particle sizes smaller than $10 \mathrm{~nm}$. This observation is explained by the high surface area of small powders, which requires a more homogeneous distribution of the dopant, i.e. a higher doping concentration to achieve the same decrease in sintering temperature as more coarse powders with particle sizes larger than $100 \mathrm{~nm}$. The combined use of a very fine powder $(<10 \mathrm{~nm})$ and of doping with cobalt oxide makes dense microstructures possible with average grain sizes smaller than $100 \mathrm{~nm}$.

\section{References}

1. R.L. Coble, J. Appl. Phys., 32, 787 (1961).

2. R.J. Brook, in Treatise on Materials Science and Technology, edited by F.F.Y. Wang (Academic Press, New York, 1976), p. 331.

3. R.L. Coble, in 5th International Round Table Conference on Sintering, edited by D. Kolar, S. Pejovnik and M.M. Ristic (Elsevier Scientific Publishing Company, Amsterdam, 1981), p. 145.

4. R.M. German and B.H. Rabin, Powder Metallurgy, 28, 7 (1985).

5. R.M. German, Sintering Theory and Practice (Wiley, New York, 1996), p. 209.

6. C.J. Li and R.M. German, Metall. Trans. A, 14, 2031 (1983).

7. J. Wong, J. Appl. Phys., 51, 4453 (1980).

8. M.N. Rahaman, L.C. Dejonghe, J.A. Voigt, and B.A. Tuttle, J. Mat. Sci., 25, 737 (1990).

9. T. Senda and R.C. Bradt, J. Am. Cer. Soc., 73, 106 (1990).

10. J. Luo and Y.-M. Chiang, Acta Materialia, 48, 4501 (2000).

11. J. Luo, H. Wang and Y.-M. Chiang, J. Am. Ceram. Soc., 82, 916 (1999).

12. C. Kleinlogel and L.J. Gauckler, Adv. Mater., 13, 1081 (2001).

13. C. Kleinlogel and L.J. Gauckler, Solid State Ionics, 135, 567 (2000).

14. T.S. Zhang, P. Hing, H. Huang, and J. Kilner, J. Eur. Cer. Soc., 21, 2221 (2001).

15. T.S. Zhang, P. Hing, H.T. Huang, and J. Kilner, Solid State Ionics, 148, 567 (2002).

16. G.S. Lewis, A. Atkinson, and B.C.H. Steele, J. Mat. Sci. Lett., 20, 1155 (2001).

17. M. Chen, B. Hallstedt, N.A. Grundy, and L.J. Gauckler, J. Am. Ceram. Soc., 86, 1567 (2003).

18. E. Jud, C.B. Huwiler, and L.J. Gauckler, accepted for publication in J. Am. Ceram. Soc.

19. E. Jud, C.B. Huwiler, and L.J. Gauckler, in preparation.

20. G.S. Lewis, A. Atkinson, and B.C.H. Steele, in Fourth European Solid Oxide Fuel Cell Forum, edited by U. Bossel (Oberrohrdorf, Switzerland, 2000), p. 773.

21. T.S. Zhang, P. Hing, H.T. Huang, and J. Kilner, J. Mat. Sci, 37, 997 (2002).

22. R.M. German, Sintering Theory and Practice (Wiley, New York, 1996), p. 223.

23. P.L. Chen and I.W. Chen, J. Am. Ceram. Soc., 79, 3129 (1996).

24. P.L. Chen and I.W. Chen, J. Am. Ceram. Soc., 80, 637 (1997).

25. M.I. Mendelson, J. Am. Cer. Soc., 52, 443 (1969).

26. L. Maedler, W.J. Stark, and S.E. Pratsinis, J. Mat. Res., 17, 1356 (2002). 